\title{
RELACIONAMENTOS NA INTERNACIONALIZAÇÃO DE EMPRESAS FRANQUEADORAS BRASILEIRAS
}

\author{
Daula Sirimarco ${ }^{1}$ ID Jorge Ferreira da Silva ${ }^{2}$ iD Angela da Rocha $^{3}$ \\ ${ }^{1}$ Pontifícia Universidade Católica do Rio de Janeiro (PUC-Rio). Rio de Janeiro, RJ-Brasil.paula.sirimarco@gmail.com \\ ${ }^{2}$ Pontifícia Universidade Católica do Rio de Janeiro (PUC-Rio). Rio de Janeiro, RJ-Brasil. jorge1319@gmail.com \\ ${ }^{3}$ Pontifícia Universidade Católica do Rio de Janeiro (PUC-Rio).Rio de Janeiro, RJ-Brasil. amc.darocha@gmail.com
}

\section{Resumo}

Objetivo: Entender o papel do relacionamento entre franqueadores e franqueados e licenciados no processo de internacionalização, adotando como perspectiva teórica o modelo de Uppsala.

Metodologia/abordagem: A metodologia utilizada foi de estudo de casos em três empresas franqueadoras internacionalizadas. Posteriormente, as informações foram comparadas com os modelos de Uppsala (1977, 2009), usando como suporte as literaturas de franquia e licenciamento.

Originalidade /Relevância: Diversos artigos (Dant \& Grünhagen, 2014; Gomes, Carneiro e Secches, 2017; Isaac, Melo, Ogasavara e Rodrigues, 2018) apontaram que a temática relacional, especialmente no contexto internacional, é uma das áreas que requer mais estudos. O trabalho pretende ajudar a preencher essa lacuna com informações sob parcerias internacionais no licenciamento e sistema de franquia.

Principais Resultados: Identificou-se que tais empresas utilizam seus conhecimentos e suas redes para expandir seus negócios e, frequentemente, absorver informações de parceiros locais para melhorar o conhecimento de mercado e adaptar seus produtos ou serviços. A expansão internacional das empresas franqueadoras estudadas pode ser explicada tanto pelo Modelo de Uppsala original (1977) quanto pelo Modelo de Uppsala revisitado (2009). Contribuições teóricas / metodológicas: $\mathrm{O}$ estudo visa contribuir do ponto de vista teórico ao aplicar o Modelo de Uppsala nas expansões internacionais por meio de modos contratuais, mostrando a importância da rede de relacionamento. Tanto o sistema de franquia quanto o licenciamento são utilizados para expansões de baixo custo, por isso a entrada na rede local é imprescindível. Com a expansão gradual e o uso de parcerias sólidas, notase que as empresas conseguem validar a estrutura de negócio e fazer adequações, especialmente culturais, ao seu modelo de negócio.

Palavras-chave: Sistema de franquias. Internacionalização de franquias. Relação franqueador-franqueado. Licenciamento.

\section{RELATIONSHIPS IN INTERNATIONALIZATION OF BRAZILIAN FRANCHISE FIRMS}

\section{Abstract}

Objective: Understand the role of the relationship between franchisors and franchisees and licensees in the internationalization process adopting the Uppsala model as a theoretical perspective.

Methodology/approach: The methodology used was a case study in three internationalized franchising companies. Subsequently, the information was compared with Uppsala's models (1977, 2009), using franchise and licensing literature as support.

Originality / Relevance: Several articles (Dant \& Grünhagen, 2014; Gomes, Carneiro \& Secches, 2017; Isaac, Melo, Ogasavara and Rodrigues, 2018 pointed out that the relational theme, especially in the international context, is one of the areas that needs further study. This paper intends to help bridge this gap with information under international partnerships in the licensing and franchise system.

Main Results: It has been found that such companies use their knowledge and networks to expand their business and often absorb information from local partners to improve market knowledge and adapt their products or services. The international expansion of the franchising companies studied

\begin{abstract}
can be explained by both the original Uppsala Model (1977) and the revisited Uppsala Model (2009).

Theoretical/ methodologic contributions: This study aims to contribute from a theoretical point of view when applying the Uppsala Model in international expansions through contractual modes, showing the importance of the relationship network. Both the franchise system and licensing are used for low-cost expansion, which is why the insertion into the local network is essential. With the gradual expansion and solid partnerships, it is noted that companies can validate the business structure and adjust, especially on a cultural level, to their business model.
\end{abstract}

Keywords: Franchise system. Franchise internationalization. Franchisorfranchisee relationship. Licensing.

\section{RELACIONES EN LA INTERNACIONALIZACIÓN DE LAS COMPAÑIIAS DE FRANQUICIAS BRASILEÑAS}

\begin{abstract}
Resumen
Objetivo del estudio: Comprender el papel de la relación entre franquiciadores y franquiciados y licenciatarios en el proceso de internacionalización, adoptando el modelo de Uppsala como una perspectiva teórica

Metodología / abordaje: La metodología utilizada fue un estudio de caso en tres franquicias internacionalizadas. Posteriormente, la información se comparó con los modelos de Uppsala (1977, 2009), utilizando literatura de franquicias y licencias como soporte.

Originalidad / Relevancia: Varios artículos (Dant y Grünhagen, 2014; Gomes, Carneiro y Secches, 2017; Isaac, Melo, Ogasavara y Rodrigues, 2018) señalaron que el tema relacional, especialmente en el contexto internacional, es una de las áreas que necesita más estudio. El trabajo tiene la intención de ayudar a cerrar esta brecha con la información bajo alianzas internacionales en el sistema de franquicias y licencias.

Resultados principales: Se ha encontrado que tales compañías usan sus conocimientos y redes para expandir sus negocios y a menudo absorben información de socios locales para mejorar el conocimiento del mercado y adaptar sus productos o servicios. La expansión internacional de las compañías de franquicias estudiadas puede explicarse tanto por el Modelo Uppsala original (1977) como por el Modelo Uppsala revisado (2009). Contribuciones teóricas / metodológicas: El estudio tiene como objetivo contribuir desde un punto de vista teórico al aplicar el Modelo de Uppsala en expansiones internacionales a través de modos contractuales, mostrando la importancia de la red de relaciones. Tanto el sistema de franquicias como las licencias se utilizan para expansiones de bajo costo, por lo que es esencial ingresar a la red local. Con la expansión gradual y el uso de asociaciones sólidas, se observa que las empresas pueden validar la estructura comercial y hacer ajustes, especialmente culturales, a su modelo comercial.
\end{abstract}

Palabras-clave: Sistema de franquicias. Internacionalización de franquicias. Relación franquiciador-franquiciado. Licencia.

\section{Cite as / Como citar}

American Psychological Association (APA)

Sirimarco, P., Silva, J. F., \& Rocha, A., (2020, July/Sept.). Relacionamentos na internacionalização de empresas franqueadoras brasileiras. Iberoamerican Journal of Strategic Management (IJSM), 19(3), 46-66. https://doi.org/10.5585/riae.v19i3.17022. 


\section{Introdução}

Surgido nos Estados Unidos ao final do século XIX (Dant \& Grünhagen, 2014), o sistema de franquia (conhecido como Business Format Franchising) cresceu rapidamente nas décadas de 1950 e 1960. A partir dos anos 1970, este formato de negócios foi amplamente utilizado na internacionalização de empresas americanas (Hoffman, Watson \& Preble, 2016; Kedia, Ackerman, Bush \& Justis, 1994; Welch, 1989), tendo sido copiado por empresas dos mais diversos países. Alon e McKee (1999) notaram o crescimento do uso de franquias nas duas décadas anteriores por empresas que almejavam uma expansão mundial rápida.

De acordo com a International Franchise Association (IFA, 2018), os EUA dispõem atualmente de cerca de 760 mil estabelecimentos franqueados, empregando mais de oito milhões de indivíduos e gerando resultados de aproximadamente 460 bilhões de dólares. Por sua vez, o Brasil é o sexto mercado mundial em número de franquias, com 146 mil estabelecimentos franqueados, ocupando 1,2 milhão de indivíduos, com um faturamento agregado de 163 bilhões de reais (ABF, 2017). No que se refere à internacionalização, as franquias brasileiras atuam em 60 países, sendo seus principais mercados de destino Estados Unidos e Portugal, além de países da América Latina.

$\mathrm{Na}$ internacionalização, a franquia é um modo de entrada contratual em que o franqueador disponibiliza a um franqueado (sediado em outro país) sua marca e modelo de negócio, e, em contrapartida, o franqueado paga uma taxa ao franqueador (Kedia, Ackerman, Bush \& Justis, 1994). Um aspecto fundamental para o sucesso das franquias é a dimensão relacional, ou seja, de que forma é iniciado, conduzido e gerenciado o relacionamento entre franqueadores e franqueados. No ambiente internacional, este relacionamento é afetado por uma diversidade de fatores, particularmente aqueles que dizem respeito a diferenças culturais e em práticas de negócio. Assim sendo, estudos que examinem a questão do relacionamento entre franqueador e franqueados em mercados externos são relevantes, por abordarem questões consideradas cruciais para o sucesso de franquias internacionalizadas.

A literatura sobre internacionalização de franquias brasileiras é ainda incipiente. Estudos realizados no Brasil identificaram (a) motivadores da internacionalização (p.ex., Borini, Rocha \& Spers, 2012; Marques, Merlo \& Nagano, 2009); (b) características organizacionais das empresas associadas à internacionalização (p.ex., Bretas, Galetti \& Rocha, 2019); (c) processo decisório de internacionalização (p.ex., Vianna, Melo \& Ryngelbaum, 2014); e (d) gestão de franquias (p.ex., Borini et al., 2013).

Em uma revisão da literatura nacional e internacional sobre internacionalização varejista, inclusive por meio de franquias, Gomes, Carneiro e Secches (2017) verificaram que a maioria das pesquisas sobre o tema, utilizando estudos de casos, foi realizada em países desenvolvidos: de 48 estudos revisados, apenas três tinham economias emergentes como países de origem das empresas internacionalizadas. Por sua vez, Isaac, Melo, Ogasavara e Rodrigues (2018), em uma análise bibliográfica de artigos nacionais e internacionais relacionados ao tema de internacionalização de redes de franquias, identificaram 23 artigos nacionais e 66 internacionais, no período de 2001 a 2015 . Uma 
das cinco temáticas identificadas refere-se à questão das relações franqueador-franqueado no contexto internacional, com apenas nove artigos sobre o tema. Em uma avaliação da literatura internacional sobre o uso de franquias como modos de entrada, Dant \& Grünhagen (2014) salientam como uma das áreas de pesquisa o relacionamento franqueador-franqueado de países distintos, salientando os conflitos potenciais entre as partes. Estes autores clamam por "mais pesquisa em países em desenvolvimento" (p.128).

O objetivo desse estudo é, portanto, investigar o papel dos relacionamentos no processo de internacionalização de empresas brasileiras franqueadoras adotando como perspectiva teórica o modelo de Uppsala, de modo a contribuir para o entendimento de como se dá o relacionamento dos franqueadores brasileiros com seus parceiros no exterior. Para tal, o estudo investigou três empresas de diferentes setores. Foram realizadas entrevistas com gestores e levantados dados secundários, colhidos em diversas fontes. A análise de dados foi executada individualmente para cada caso, entre os casos e, por último, realizada a comparação com os padrões na literatura, de modo a atingir o objetivo de pesquisa.

\section{Referencial teórico}

Utilizou-se, como perspectiva teórica, o modelo de processo de internacionalização de Uppsala, em sua versão original (Johanson \& Vahne, 1977), e na sua versão revisitada (Johanson \& Vahlne, 2009). Além disso, considerou-se a literatura sobre internacionalização de franquias, de caráter predominantemente empírico.

\section{Internacionalização no Modelo de Uppsala}

O modelo original de Uppsala (Johanson \& Vahlne, 1977), parte do pressuposto de que a internacionalização da empresa ocorre quando o mercado nacional se encontra saturado. Para continuar crescendo, a empresa necessita expandir-se para novos mercados. O modelo sugere que a internacionalização ocorre em etapas (gradualismo), inicialmente para países de menor distância psíquica com relação ao país de origem. A distância psíquica refere-se à percepção da gerência quanto a diferenças e semelhanças entre o mercado de origem e o de destino. Esta percepção inclui fatores como idioma, desenvolvimento econômico, práticas de negócios, sistemas político e legal, infraestrutura de marketing e estrutura da indústria (Evans, Treadgold \& Mavondo, 2000). A internacionalização é vista como um processo gradual devido ao fato de a empresa comprometer seus recursos e aumentar o grau de especificidade destes à medida que obtém conhecimento tácito do mercado desejado.

No modelo de Uppsala original, o processo de internacionalização pode seguir dois padrões principais. O primeiro é conhecido como cadeia de estabelecimento (Johanson \& Wiedersheim-Paul, 1975), em que o investimento é feito de forma gradual e planejada no mercado externo, sendo adotados modos de entrada de crescente comprometimento, à medida que a empresa adquire conhecimento sobre 
o mercado. O início se dá com a exportação esporádica, podendo atingir o maior grau de comprometimento, que corresponde a uma subsidiária de produção. $\mathrm{O}$ segundo padrão refere-se à distância psíquica, que pressupõe internacionalização em mercados psiquicamente próximos, prosseguindo, para mercados percebidos como de maior distância psíquica.

Os autores revisitaram o modelo em 2009, inserindo o conceito de redes. Nesse modelo, as entidades encontram-se engajadas em atividades de troca com seus parceiros. A internacionalização é vista como um processo multilateral que facilita o sucesso da empresa no exterior (Johanson \& Vahlne, 2009), influenciando - e até mesmo determinando - a escolha de mercados e o modo de entrada.

$\mathrm{O}$ conceito de redes refere-se às conexões entre organizações que participam de um mercado. A associação pode ser formal ou informal e cada empresa participa de pelo menos uma rede (Johanson \& Mattson, 1993). A empresa se internacionaliza para mercados em que ela possui conexões de rede ou para onde participantes da sua rede atual estão se deslocando.

\section{Internacionalização por modos contratuais: franquia e licenciamento}

Os principais modos contratuais de internacionalização são a franquia e o licenciamento. No sistema de franquia, o detentor da marca - o franqueador - concede a uma pessoa física ou jurídica - o franqueado - o direito de conduzir o negócio em regiões diversas. $\mathrm{O}$ franqueador exige o pagamento de taxas e controla os níveis de padronização, qualidade e serviço (Marques, Merlo \& Nagano, 2009; Guetta et al., 2013). O contrato de franquia estabelece uma relação de subordinação. O controle é necessário para verificar se o franqueado está de acordo com as normas institucionais da franqueadora (Brooke \& Altinay, 2017).

Segundo Brouthers e McNicol (2009), o licenciamento internacional produz oportunidades relevantes para as empresas. O licenciamento não requer investimentos das partes e normalmente é utilizado como canal de distribuição para capturar economias de escala e impulsionar o crescimento e desenvolvimento da empresa. $\mathrm{O}$ acordo de licenciamento é oficializado via contrato que estabelece as trocas relacionais entre os participantes. $\mathrm{O}$ aprendizado compartilhado entre parceiros, neste tipo de negociação, permite a inovação e diminui os custos (Brouthers \& McNicol, 2009; Cavusgil, 1998).

A Tabela 1 faz uma comparação entre licenciamento e franquia internacional no que se refere a suas características e benefícios. 
Tabela 1 - Comparação entre franquia e licenciamento internacional sob a perspectiva do franqueado

\begin{tabular}{|l|l|l|}
\hline & \multicolumn{1}{|c|}{ Franquia } & \multicolumn{1}{|c|}{ Licenciamento } \\
rísticas & $\begin{array}{l}\text { Franqueador desenvolve a marca e oferece } \\
\text { produtos padronizados. }\end{array}$ & $\begin{array}{l}\text { Licenciamento pode cobrir marca, patente } \\
\text { ou sistema operacional sem necessidade de } \\
\text { desenvolver um negócio padronizado }\end{array}$ \\
\cline { 2 - 3 } & $\begin{array}{l}\text { Franqueador estipula responsabilidades, direitos } \\
\text { de decisão e lucros para o franqueado, com meta } \\
\text { pré-determinada de qualidade }\end{array}$ & $\begin{array}{l}\text { Licenciado gerencia o próprio negócio sem } \\
\text { metas pré-determinadas de qualidade. }\end{array}$ \\
\cline { 2 - 3 } & $\begin{array}{l}\text { Forte componente de serviços do franqueador ao } \\
\text { franqueado }\end{array}$ & $\begin{array}{l}\text { Venda apenas de conhecimento } \\
\text { proprietário }\end{array}$ \\
\hline Benefícios & $\begin{array}{l}\text { Força da marca permite obter economias de escala } \\
\text { mais rapidamente }\end{array}$ & $\begin{array}{l}\text { Força da marca permite atrair novos } \\
\text { clientes }\end{array}$ \\
\cline { 2 - 3 } & $\begin{array}{l}\text { Serviços associados à franquia (por ex.: processo } \\
\text { de produção, modelo de negócio etc.) }\end{array}$ & $\begin{array}{l}\text { Apenas assistência técnica (quando há } \\
\text { transferência de produto ou tecnologia) }\end{array}$ \\
\cline { 2 - 3 } & Eficiência em informação, supervisão e escala & $\begin{array}{l}\text { Potencial redução de custos de } \\
\text { desenvolvimento }\end{array}$ \\
\cline { 2 - 3 } & $\begin{array}{l}\text { Maior possibilidade de crescimento e } \\
\text { sobrevivência da empresa }\end{array}$ & \\
\hline & $\begin{array}{l}\text { Criação de valor para o franqueado graças à } \\
\text { reputação da franquia }\end{array}$ & \\
\hline
\end{tabular}

Fonte: Adaptado de Brouthers e McNicol (2009, p. 186)

$\mathrm{Na}$ literatura de negócios internacionais, admite-se que as empresas franqueadoras podem utilizar diversos modos de entrada em mercados externos: (i) unidades próprias; (ii) franquia direta; (iii) máster franqueado; (iv) joint venture; e (v) subsidiárias com escritório próprio (Aliouche \& Schlentrich, 2011; Quinn \& Alexander, 2002). Cada modo de entrada está conectado a um nível de controle e investimento (Jell-Ojobor \& Windsperger, 2014). Naturalmente, as empresas podem utilizar simultaneamente diversos modos em mercados distintos.

Para Alon, Boulanger, Misati \& Madanoglu (2015), a utilização de máster franquia implica menor controle, investimento e comprometimento do que a adoção de franquia direta. O contato dos franqueados passa a ser com a estrutura do máster franqueado, o que torna mais difícil à empresa franqueadora obter conhecimento sobre os seus franqueados. Além disto, se ocorrer falha na escolha de parceiros locais, problemas legais podem se avolumar. São desvantagens potenciais relacionadas a este modo de entrada.

Os franqueados inseridos na realidade local dispõem de conhecimento sobre o mercado local. Além do conhecimento explícito, por meio de obrigações contratuais e manuais de uso, o franqueador necessita adquirir conhecimento tácito dos parceiros (Brookes \& Altinay, 2017). As redes de relacionamentos e os laços estreitos com os parceiros incentivam a comunicação (Baena, 2018; Brookes \& Altinay, 2017). Muitos franqueadores utilizam viagens internacionais, treinamentos, redes sociais e plataforma virtuais para tal. 
O processo de internacionalização é dinâmico e exige constante adaptação e ajuste das atividades empresariais (Altiney \& Okumus, 2010; Tang, 2009). Para Altinay e Okumus (2010), a internacionalização de franquia acontece por meio de um processo integrado e dinâmico devido às diferenças culturais entre as partes. Por isso, as parcerias devem envolver avaliação mútua e cuidadosa entre os parceiros para verificar se os objetivos são compatíveis (Brookes \& Altinay, 2011).

Para Davies et al. (2011), potenciais conflitos e insatisfação do franqueado originam-se, em parte, de possível excesso de controle, que limita a autonomia do parceiro externo. Neste sentido, a falta de conformidade do franqueado com as normas da franquia pode ser entendida como uma reação à incapacidade do franqueador de corresponder às expectativas no longo prazo. Como consequência, a confiança entre os parceiros pode ficar abalada. Por isso a relação precisa sustentar níveis de confiança elevados, para evitar comportamentos não desejados. O comprometimento e a confiança entre os parceiros pressupõem um processo de trocas recíprocas (Altinay et al., 2014).

A satisfação do franqueado juntamente com os conflitos enfrentados determinam o nível de confiança entre as partes (Davies et. al, 2011). De acordo com Altinay et al. (2014), o relacionamento entre franqueado e franqueador é interdependente e mútuo. As partes têm seus próprios interesses e buscam benefícios específicos. É importante, portanto, que os relacionamentos sejam estimulados por meio de comunicações e interações constantes.

Se há um entendimento entre as partes, a confiança e o comprometimento são construídos, os laços criados e o aprendizado mútuo acontece (Altinay et al., 2014). Franqueados satisfeitos com o suporte recebido pela marca têm mais confiança na capacidade do franqueador (Brookes \& Altinay, 2011).

Assim, a literatura aponta para a importância da rede de relacionamento na internacionalização, o que se evidencia pelo ônus de a empresa estar fora das redes em seus mercados de atuação. Essa questão sobressai quando se consideram os modos contratuais, tais como franquia e licenciamento, em que se estabelecem parcerias de longo prazo, salientando o papel da confiança, do aprendizado relacional e do comprometimento mútuo.

\section{Metodologia}

Utilizou-se o método de pesquisa de estudo de casos múltiplos (Eisenhardt, 1989; Yin, 2009), considerado adequado para examinar aspectos do fenômeno de internacionalização de franqueadoras brasileiras. O método possibilita entender (i) como se comportam relações emergentes e a dinâmica subjacente a tais relações; e (ii) as conexões entre fatores ambientais, do setor e dos parceiros (Eisenhardt, 1989; Ghauri, 2004).

Os critérios para seleção dos casos foram: (i) ser uma empresa franqueadora no Brasil; (ii) ter operações internacionais em diversos países; (iii) ser relevante em seu setor de atuação; e (iv) concordar em colaborar com o estudo. Três casos foram selecionados: Alfa Piscinas, fabricante de piscinas, 
Usaflex, do setor de calçados, e Localiza, que atua em locação de veículos. Alfa Piscinas é um nome fictício.

Foram coletados dados primários e secundários. Os dados primários foram obtidos por meio de entrevistas em profundidade, utilizando roteiro semiestruturado. Os dados secundários foram colhidos em sítios de internet e reportagens sobre as empresas. Foram entrevistados executivos das empresas diretamente envolvidos com suas atividades de internacionalização. O roteiro da entrevista cobriu quatro grandes temas: histórico da empresa, processo de internacionalização, características dos parceiros e aprendizado na internacionalização. A triangulação de fontes permitiu garantir a validade e a confiabilidade da investigação.

A análise de dados foi executada em três etapas: análise dos casos isoladamente (within-case analysis), comparação entre os casos (cross-case analysis) e análise de padrões (pattern matching), que consiste no confronto dos resultados com as perspectivas teóricas adotadas (Ghauri, 2004; Yin, 2009). Os resultados obtidos foram comparados com categorias extraídas do modelo de Uppsala original (Johanson \& Vahlne, 1977) e modelo revisitado (Johanson; Vahlne, 2009). No modelo de Uppsala original, as categorias relevantes foram: (i) cadeia de estabelecimento; (ii) distância psíquica aos mercados e (iii) gradualismo. As categorias utilizadas para confronto com o modelo de Uppsala Revisitado foram: (i) uso de parcerias/rede; (ii) comprometimento com a rede e (iii) aprendizado com a rede. Foram estabelecidos os seguintes critérios de avaliação: alto - três condições atendidas; médio duas condições atendidas; baixo - uma condição atendida; nulo - nenhuma condição atendida.

\section{Descrição dos casos}

Apresenta-se a seguir uma breve descrição dos três casos estudados: Alfa Piscinas, Localiza e Usaflex.

\section{Alfa Piscinas}

A empresa foi criada em 1995 na região Sul do Brasil. Seus produtos consistem principalmente em piscinas de fibra de vidro. A empresa usa o sistema de franquias, tendo mais de 800 franquias, sendo cerca de 170 no exterior. Conta com aproximadamente cinco mil colaboradores (diretos e indiretos).

A atuação internacional da Alfa Piscinas teve início em 2002, exportando produtos para a Argentina. Posteriormente, em 2005, expandiu para esse mesmo país, com uma fábrica em joint venture com parceiro local. Em movimento subsequente, a empresa se estabeleceu em Portugal, novamente em joint venture de fabricação com parceiro local. A empresa dispõe de 46 fábricas, localizadas no Brasil, Portugal, Argentina, México e Paraguai. Sua atuação se concentra na América Latina, principalmente na Argentina, onde tem a principal fábrica internacional, que abastece outros mercados latinoamericanos.

A sequência de entrada em mercados externos é apresentada na Figura 1. 
Figura 1 - Linha do tempo da internacionalização da Alfa Piscinas

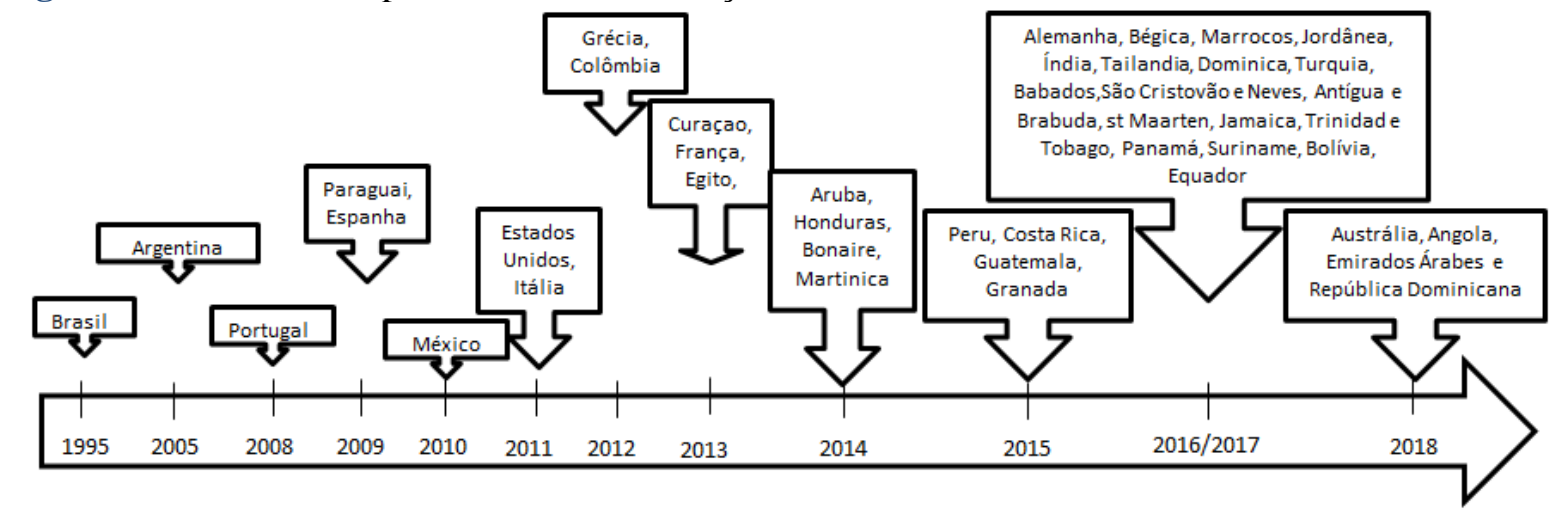

Fonte: Autores.

O parceiro de fabricação local é também o máster franqueado para a região abarcada pela fábrica. A seleção dos franqueados é realizada pelo máster franqueado da região, juntamente com o diretor da Alfa Piscinas responsável pela expansão internacional da empresa. A utilização de indivíduos oriundos do Brasil na internacionalização é considerada relevante, tendo em vista que esses parceiros dispõem de conhecimento tanto relativo à cultura da empresa quanto à cultura do país, o que, na opinião da gerência, torna a comunicação mais fácil.

A gerência da empresa vê, como principal vantagem de ter como franqueado um parceiro local, a oportunidade de obter conhecimento mais aprofundado dos costumes locais, o que, aliado à expertise de mercado da empresa, leva a uma penetração mais eficaz dos produtos no país. O desconhecimento pela empresa da forma de fazer negócios no país pode gerar tensão entre as partes ou até um desalinhamento na estratégia da empresa. Por exemplo, a escolha do México como mercado levou em consideração parâmetros como idioma, clima, tamanho da população, perfil e tamanho da economia. No entanto, a empresa se deparou com diferenças culturais inesperadas entre franqueados brasileiros e franqueados mexicanos que impactaram negativamente a gestão do negócio.

À medida que a empresa se expandia no exterior, foi aprendendo, na prática, como operar. Por exemplo, inicialmente a empresa escolhia como parceiros para abrirem franquias no exterior brasileiros que tivessem interesse em morar no exterior. No entanto, a falta de contatos locais desses indivíduos dificultava a aceitação pelo mercado. Por conta desta experiência, a Alfa Piscinas passou a trabalhar com franqueados locais, que já detivessem uma rede de relacionamentos de negócios no país estrangeiro.

Atualmente, a empresa tem seguido uma espécie de protocolo para a seleção de franqueados potenciais. Parte-se da identificação de características necessárias em um parceiro no mercado-alvo. Selecionado o parceiro, as trocas sociais acontecem de forma gradual, gerando aprendizado para ambas as partes. A interdependência entre empresa e parceiro faz com que a confiança se estabeleça e os laços entre as partes sejam fortalecidos. À medida que cresce o comprometimento mútuo, torna-se mais fácil realizar adaptações no produto e obter maior penetração de mercado. Mecanismos usados para fortalecer o relacionamento entre a empresa e os parceiros incluem treinamento, convenções de venda, visitas e workshops. Para manter aberto o fluxo de informação entre as partes utiliza-se intranet, whatsapp, 
contato telefônico direto e e-mail. Para soluções urgentes, a empresa disponibiliza uma área de suporte, com pronto atendimento, rápido e personalizado. A Alfa Piscinas também implementou um banco de dados interno. A intranet é o canal de comunicação dentro da empresa, mas há também uma rede social interna em que os parceiros podem publicar informações específicas e em que a empresa divulga comunicados, avisos, anúncios e previsões.

O controle das franquias internacionais é feito pelas equipes de expansão e pelos máster franqueados da região, que enviam relatórios e fazem reuniões com a diretoria da empresa para repassar as informações obtidas. Para evitar o desalinhamento de interesses, a empresa costuma acompanhar o desempenho das lojas franqueadas e verificar possíveis medidas a serem tomadas preventivamente.

A principal fonte potencial de conflitos decorre de diferenças culturais. É preciso aprender a conviver com diversas culturas dentro da empresa. Uma vantagem apontada pelo entrevistado para este conhecimento ser absorvido mais facilmente é a existência de máster franqueados. Pelo fato de serem brasileiros e morarem há algum tempo nas regiões-alvo, os máster franqueados já teriam desenvolvido as habilidades necessárias para assimilar as diferenças. Assimilar a cultura de outro país significa entender que a forma usual de condução de negócios pela empresa pode não ser a melhor para o parceiro. Por isso, é preciso aprender que adaptações são necessárias para cada mercado, sem esquecer que manter os padrões é primordial para preservar a identidade da Alfa Piscinas e para que os consumidores associem qualidade ao produto.

A partir do aprendizado obtido, a modalidade de franquia se tornou próspera para o negócio da empresa. Assim, a Alfa Piscinas conseguiu internacionalizar-se com êxito por meio do sistema de franquia.

\section{Localiza}

A Localiza foi fundada em 1973, em Belo Horizonte. Tem como atividade principal a locação de veículos. Foi uma das primeiras adeptas da modalidade de franquia no Brasil, criando seu sistema em 1983. Posteriormente, em 1992, foi uma das pioneiras brasileiras no mercado internacional.

A Localiza é a empresa que possui maior índice de internacionalização (média dos índices de receitas, ativos e funcionários) entre franqueadoras e maior proporção de unidades franqueadas no exterior (30\%) (FDC, 2017). Sua atuação no exterior é focada na América do Sul. A Localiza iniciou seu processo de internacionalização para se beneficiar de novas possibilidades e oportunidades que poderiam surgir com a criação do Mercosul, além de reduzir sua vulnerabilidade a flutuações do mercado interno. Atualmente a empresa dispõe de 583 agências, sendo 127 franquias, mais de 7500 colaboradores e uma frota de quase 200 mil carros, sendo 15 mil destinados exclusivamente a aluguel no sistema de franquia. Sua atuação internacional está focada em seis países: Argentina, Paraguai, Uruguai, Colômbia, Chile e Equador (Figura 2). A empresa não forneceu dados específicos quanto ao 
ano de entrada em cada um dos países da América do Sul em que opera, mas apenas o período em que entrou nesses mercados.

Figura 2 - Linha do tempo - internacionalização Localiza

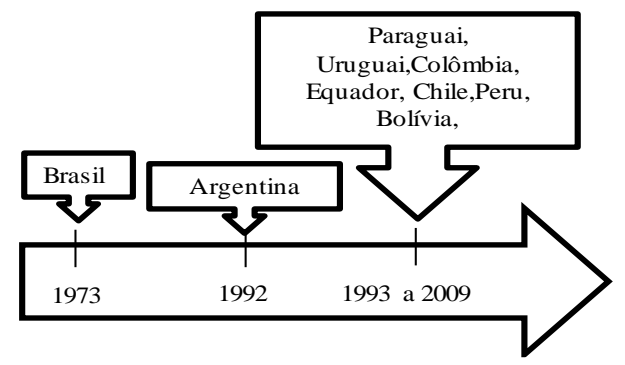

Fonte: Autores.

A empresa possui oito franqueados no exterior e 60 no Brasil. A orientação estratégica é ter lojas próprias somente no Brasil. A expansão internacional é feita por meio de máster franqueados, por se tratar de um negócio intensivo em capital e para mitigar riscos relacionados ao desconhecimento de leis e costumes locais. A Localiza trabalha com grandes grupos como franqueados e é comum um franqueado operar várias unidades.

A utilização de parceiros locais é vista pela empresa como a melhor opção de internacionalização. O operador local detém conhecimentos específicos relativos ao ambiente institucional e regulatório, o que simplifica e acelera o processo de abertura de lojas. Outra vantagem desse modelo de parceria é que faz com que a empresa tenha um posicionamento mais assertivo. Uma experiência no Peru, com a seleção de um franqueado colombiano, passou por vários impasses legais e de regulamentação, até que este foi substituído por um parceiro local, peruano, que rapidamente resolveu o problema.

O negócio da Localiza se baseia em três pilares: compra, aluguel e venda de veículos. Os parceiros internacionais não precisam, necessariamente, ter experiência abrangente no setor, mas é desejável ter experiência em compra e venda ou aluguel de carros. Outra característica relevante para a empresa é ter capacidade financeira para investir na franquia, dado que a empresa trabalha com um ativo que se deprecia e as frotas precisam ser ampliadas ou renovadas com frequência.

A gerência da empresa acredita ser essencial a confiança entre as partes. A contribuição do franqueador começa com as orientações e sugestões para que o operador construa um negócio rentável. A vertente financeira é imprescindível, mas não suficiente para que a relação se estabeleça. A Localiza também trabalha a parte motivacional, com premiações de reconhecimento. Outro fator que cria confiança, na opinião do gestor, são os valores éticos da marca, que beneficiam a construção do relacionamento e a inserção na rede.

Os canais formais, como intranet, são usados para disponibilização de conteúdo de orientação, tais como manuais on-line e treinamentos virtuais. O e-mail é usado para formalizar alguma situação, o WhatsApp quando o assunto requer agilidade e o Skype para treinamentos ao vivo. A empresa também 
realiza treinamentos presenciais, quando necessário. Normalmente, o treinamento envolve fatores de qualidade na prestação de serviço ou demandas recorrentes recebidas por meio do canal de atendimento aos franqueados. Visitas são feitas, pelo menos uma vez ao ano, pela equipe internacional da marca.

A principal desvantagem de se trabalhar com um parceiro local, na visão da gerência, relacionase ao controle da operação: como a empresa trabalha com prestação de serviços, faz-se necessário monitorar constantemente a padronização das lojas e a consistência do atendimento prestado, sob pena de gerar desempenho pouco satisfatório e perda de qualidade. O grande desafio é o fato de o franqueado ser um cliente da empresa, mas, ao mesmo tempo, ter que seguir diretrizes estabelecidas pela Localiza.

Muitas vezes, o controle da qualidade do serviço prestado pela empresa pode gerar conflitos entre as partes. Outro fator que pode contribuir para desavenças é a diferença de horizontes de investimentos, pois o franqueado pode privilegiar estratégias de curto prazo em detrimento de uma visão de longo prazo do franqueador. Diferenças culturais também podem gerar atritos, quando se trata de atendimento ao cliente. A empresa possui regras que precisam ser atendidas em todas as lojas franqueadas. Um exemplo disso é o cliente alugar determinada categoria de carro e, ao chegar à loja, não encontrar o carro na categoria reservada. Nesse caso, o franqueado é obrigado a entregar um carro de categoria superior. Caso não exista disponibilidade, pode ser um carro de categoria inferior, mas livre de qualquer cobrança até o carro reservado chegar. Para o entrevistado, se não houver confiança entre as partes, o franqueado pode considerar as regras muito rígidas e até se sentir lesado. Conflitos podem ser contornados quando há um clima de confiança entre franqueador e franqueado. Normalmente, por manter um relacionamento próximo, há diálogo entre as partes, os problemas são solucionados e muitos deles até antecipados. $\mathrm{O}$ acompanhamento constante do franqueado possibilita à empresa flexibilizar alguns pontos para atender a especificidades locais, mas isso não é muito desejável na modalidade de franquia.

Usaflex

A Usaflex foi criada em 1998, no Rio Grande do Sul, em Igrejinha. A empresa atua no setor calçadista, com produtos predominantemente de couro, sendo líder no segmento de calçados que oferecem conforto aos usuários. Dispõe de quatro unidades produtivas, todas no Rio Grande do Sul, e tem cerca de 2.800 empregados diretos.

Em 2016 um fundo de private equity adquiriu 69\% da Usaflex. A partir desta aquisição, a empresa começou a expandir seu modelo de franquia no país, e passou a fazer licenciamento no exterior.

Embora a empresa já exportasse há mais de 15 anos, sua internacionalização se intensificou a partir de 2017, devido à mudança societária, que deu maior ênfase ao licenciamento no exterior. A linha do tempo referente ao processo de internacionalização da empresa é apresentada na Figura 3, mas inclui apenas mercados externos a partir de 2017. 
Figura 3 - Linha do tempo da Internacionalização da Usaflex

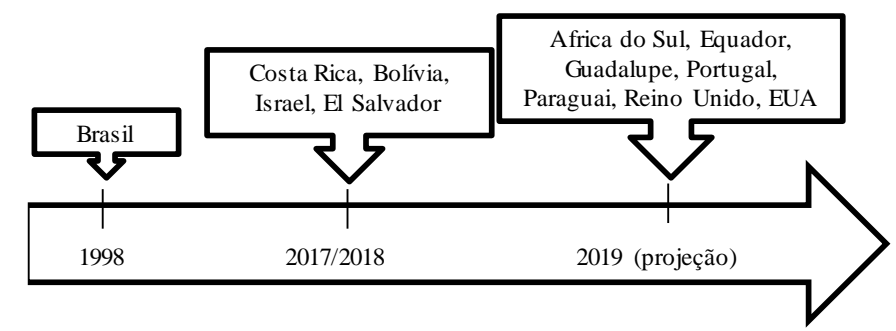

Fonte: Autores.

A partir de 2017, as lojas internacionais da Usaflex são acordadas por meio de licenciamento. O executivo-chefe da empresa explicou que a expansão internacional via licenciamento e não franquia, como no Brasil, se deve ao fato de a empresa desconhecer, ou possuir conhecimento muito superficial, sobre legislação e regulamentação nos países estrangeiros. Este conhecimento estaria mais disseminado entre os empresários locais. O entrevistado também mencionou que uma operação de franquia no exterior tem custo elevado, pois um contrato de franquia requer que o franqueador dê suporte de gestão, jurídico, arquitetônico, de marketing, entre outros. Em troca, o franqueado paga taxas para utilizar a marca e obter a transferência de conhecimento sobre o negócio. Levando em conta estas características a empresa optou por licenciar no exterior, considerando que a modalidade proporciona mais liberdade às partes.

No licenciamento, realizado pela Usaflex, há obrigatoriedade de usar o mesmo padrão arquitetônico aplicado no Brasil. Os licenciados pagam uma taxa e o contrato vigora por cinco anos. Alguns parceiros já importavam os produtos para suas lojas multimarcas e se interessaram em abrir uma loja da Usaflex devido à boa vendagem dos produtos. Outros passaram a conhecer a marca por meio de feiras internacionais.

Uma característica importante para que o candidato se torne parceiro da empresa é ser um player do setor de calçados no seu país. A única exceção é o licenciado de Israel, que não atuava no mercado local. Ser conhecido e conhecer o mercado local é um diferencial competitivo e, consequentemente, uma vantagem para este tipo de parceria, por já conhecer a cultura do país e entender as características dos consumidores. O mercado dos Estados Unidos é considerado estratégico e, na equipe internacional, há uma pessoa exclusiva para atender esse mercado. Por se tratar de um mercado muito competitivo, a Usaflex requer que o sócio local possua alta capacidade de investimento. Como não há obrigatoriedade de compra de nenhum item da Usaflex, o parceiro monta o mix baseado em seus conhecimentos do mercado local.

Mesmo havendo riscos e custos mais baixos no licenciamento, é necessário construir um relacionamento de confiança entre as partes. Para que isso se concretize, faz-se um trabalho de envolvimento com os parceiros, expondo os valores da empresa e buscando conhecer as características dos mercados estrangeiros. A empresa montou uma universidade corporativa que contribui para disseminar dados e aspectos emocionais relacionados à marca. Por este meio, transfere informações para 
funcionários e colaboradores de como a Usaflex deseja tratar os clientes. Isso, na opinião do entrevistado, ajuda na padronização e consolidação da marca.

A Usaflex dispõe de uma equipe internacional, que é composta por um executivo de mercado e três assistentes. A inauguração da loja tem como um dos pré-requisitos a validação do layout, que é feita por essa equipe. São feitas visitas duas vezes ao ano aos países com volume de vendas elevado. Caso a parceria seja bem-sucedida, o contrato é renovado. Os parâmetros de avaliação são volume de vendas e expectativa de resultados, dentre outros. O acompanhamento das vendas das lojas licenciadas possibilita uma visão sistêmica dos resultados da empresa por região e permite tornar mais próximos os laços com os parceiros. Os canais de comunicação estabelecidos pela Usaflex com os licenciados são e-mail, telefone ou WhatsApp. Em 2019, a Usaflex lançou sua plataforma de e-commerce, que permite acesso ao portfólio de produtos pelos clientes institucionais.

A relação de confiança entre as partes vai se estreitando à medida que o parceiro vai conhecendo a Usaflex, seus valores, o padrão de qualidade dos produtos e o respeito da Usaflex pelos clientes e licenciados. Na opinião do entrevistado, são raros os conflitos. Mas podem ocorrer comportamentos oportunistas de terceiros, que veem valor na marca e tentam obter vantagens financeiras por meio de trâmites jurídicos locais.

$\mathrm{O}$ aprendizado pode ser absorvido por meio de experiências bem ou não tão bem-sucedidas. $\mathrm{O}$ entrevistado relatou o caso de um parceiro - uma marca internacional - que, à época, exigia produtos de qualidade muito superior aos demais parceiros da Usaflex na América Latina. Um lote fabricado pela Usaflex para este cliente foi recusado no quesito qualidade. Em uma demonstração de comprometimento com a parceria, a empresa refez todos os produtos sem custo adicional. A experiência deixou clara a necessidade de investir em qualidade e melhoria nos processos e produtos, para atender às expectativas dos clientes e demonstrar aos parceiros o comprometimento da Usaflex.

\section{Análise comparativa dos casos}

A análise comparativa dos casos estudados é dividida em duas partes. Primeiro, comparam-se os processos de internacionalização das empresas. Em seguida, realiza-se uma comparação dos sistemas de parceria adotados no processo de internacionalização.

\section{Comparação dos processos de internacionalização}

Embora as três empresas sejam franqueadoras brasileiras, duas empresas utilizam franquia em sua atuação internacional (Alfa Piscinas e Localiza), enquanto a Usaflex utiliza licenciamento. É interessante observar que a empresa que optou por licenciamento no exterior é exatamente a que se internacionalizou mais recentemente (2003 - exportação e 2016 - lojas licenciadas). Observa-se ainda que duas empresas começaram com exportação e só depois adotaram a franquia ou o licenciamento. Todas escolheram o primeiro mercado com baixa distância psíquica. As três empresas ainda têm, em 
2018, uma atuação predominante na própria região de origem (América Latina ou América do Sul). Nenhuma empresa estudada realizou investimento direto no exterior.

Tabela 2 - Comparação do Processo de Internacionalização das Empresas Estudadas

\begin{tabular}{|l|l|l|l|}
\hline \multicolumn{1}{|c|}{ Características } & \multicolumn{1}{c|}{ Alfa Piscinas } & \multicolumn{1}{c|}{ Localiza } & \multicolumn{1}{c|}{ Usaflex } \\
\hline Ano de internacionalização & 2002 & 1992 & 2003 \\
\hline $\begin{array}{l}\text { Anos entre fundação e } \\
\text { internacionalização }\end{array}$ & 7 & 19 & 5 \\
\hline $1^{\circ}$ modo de entrada utilizado & Exportação & Franquias & Exportação \\
\hline $1^{\circ}$ mercado externo & Argentina & Argentina & Costa Rica \\
\hline$N^{\circ}$ de mercados externos - 2018 & 45 & 6 & 4 \\
\hline Região do mundo de maior atuação & Am. Latina & Am. do Sul & Am. Latina \\
\hline Modos de operação - 2018 & $\begin{array}{l}\text { Fábricas (joint- } \\
\text { venture) e franquia } \\
\text { (Brasil/exterior) }\end{array}$ & $\begin{array}{l}\text { Lojas próprias } \\
\text { (Brasil); franquias } \\
\text { (Brasil/exterior) }\end{array}$ & $\begin{array}{l}\text { Fábricas e franquias } \\
\text { (Brasil); licenciamento } \\
\text { (exterior) }\end{array}$ \\
\hline Lojas de parceiros no exterior - 2018 & $>170$ & 61 & 10 \\
\hline
\end{tabular}

Fonte: Autores

\section{Comparação dos sistemas de parceria adotados pelas empresas}

Duas empresas utilizam a forma contratual de máster franquias, que pagam royalties e taxa para a franqueadora. A escolha dessa modalidade faz com que a empresa delegue a escolha dos franqueados ao máster franqueado. É considerado um critério importante que o franqueado esteja alinhado com a política, valores e objetivos da empresa franqueadora.

A Alfa Piscinas estruturou suas fábricas com capital misto (próprio e de terceiros) e tornou esses parceiros seus máster franqueados. Na escolha de máster franqueados, há preferência por brasileiros. Por meio das fábricas, os franqueados recebem o suporte, treinamento e transferência de conhecimentos. Os máster franqueados da Localiza são investidores capitalistas e normalmente atuam em todo o território do país estrangeiro. Há predileção por indivíduos locais já familiarizados com os costumes e trâmites legais do país. Como a Localiza oferece serviços, é importante ter um parceiro local que entenda a cultura e os costumes. Assim, a gerência da empresa acredita que este máster franqueado consegue implementar, mais assertivamente, a marca no país. Por sua vez, a Usaflex não utiliza o sistema de franquia no exterior, mas procura parceiros com redes estabelecidas e negócios já implementados no setor, licenciando a abertura de lojas da marca.

A Tabela 3 resume esta comparação. 
Tabela 3 - Comparação dos Sistemas de Parceria das Empresas

\begin{tabular}{|l|l|l|l|}
\hline \multicolumn{1}{|c|}{ Característica } & \multicolumn{1}{|c|}{ Alfa Piscinas } & \multicolumn{1}{|c|}{ Localiza } & \multicolumn{1}{c|}{ Usaflex } \\
\hline Tipo de Parceiros & $\begin{array}{l}\text { Máster franqueado e } \\
\text { franqueados }\end{array}$ & $\begin{array}{l}\text { Máster franqueado e } \\
\text { franqueados }\end{array}$ & Licenciados \\
\hline $\begin{array}{l}\text { Nacionalidade } \\
\text { dos parceiros }\end{array}$ & $\begin{array}{l}\text { Principalmente } \\
\text { brasileiros para máster } \\
\text { franquias e locais para os } \\
\text { franqueados }\end{array}$ & $\begin{array}{l}\text { Preferencialmente } \\
\text { parceiros locais }\end{array}$ & Empresários locais \\
\hline $\begin{array}{l}\text { Fatores para gerar } \\
\text { confiança }\end{array}$ & $\begin{array}{l}\text { Marca da empresa } \\
\text { Retorno financeiro } \\
\text { Alinhamento de } \\
\text { expectativas } \\
\text { Acesso a informações }\end{array}$ & $\begin{array}{l}\text { Relacionamento próximo } \\
\text { Transferência de Know } \\
\text { how } \\
\text { Valores éticos da marca }\end{array}$ & $\begin{array}{l}\text { Visitas à fábrica e à sede } \\
\text { Conhecimento sobre a empresa } \\
\text { e os conceitos aplicados } \\
\text { Comprometimento com a } \\
\text { operação de licenciamento }\end{array}$ \\
\hline $\begin{array}{l}\text { Sistema de } \\
\text { controle }\end{array}$ & $\begin{array}{l}\text { Relatórios } \\
\text { Reuniões } \\
\text { Equipe internacional }\end{array}$ & $\begin{array}{l}\text { Sistemas próprios para } \\
\text { acompanhar a evolução } \\
\text { das operações }\end{array}$ & $\begin{array}{l}\text { Padronização de lojas } \\
\text { Controle de vendas } \\
\text { Renovação do contrato atrelado } \\
\text { ao volume de vendas }\end{array}$ \\
\hline Tipos de conflitos & $\begin{array}{l}\text { Não alinhamento de } \\
\text { objetivos/estratégia } \\
\text { Diferenças culturais } \\
\text { Resistência a } \\
\text { coordenação }\end{array}$ & $\begin{array}{l}\text { Prazos de investimentos } \\
\text { distintos } \\
\text { Conflitos de expectativa }\end{array}$ & $\begin{array}{l}\text { Problemas jurídicos devido ao } \\
\text { desconhecimento das leis locais } \\
\text { Comportamentos oportunistas. }\end{array}$ \\
\hline
\end{tabular}

Fonte: Autores.

No que se refere aos conflitos com os franqueados, as duas empresas que utilizam franquia nos mercados externos apontam como principal fonte de conflitos o não alinhamento de visões entre franqueador e franqueado (podendo se referir a objetivos, estratégias, expectativas e prazos de investimento). Isto é consistente com o estudo de Brookes e Altinay (2011), que sugere que o estabelecimento de uma parceria por meio de máster franquia deve envolver avaliações mútuas e criteriosas entre as partes. A Localiza enfatizou ainda a diferença de percepção no horizonte de investimento. O negócio de aluguel de veículos requer investimento significativo e muitas vezes o franqueado deseja ações de curto prazo. O franqueador por sua vez busca a consolidação da marca e pode querer adotar ações de longo prazo causando desalinhamento nas estratégias. A zona de conforto financeira foi outro exemplo dado pela Alfa Piscinas. Já para a Usaflex, que utiliza licenciamento, a fonte principal de conflitos é o desconhecimento do ambiente de negócios no país estrangeiro.

\section{Comparação com o Modelo de Uppsala (Pattern-Matching Analysis)}

Nesta seção faz-se uma comparação entre os três casos e o modelo de Uppsala em suas duas versões: original (Johanson \& Vahlne, 1977) e revisitada (Johanson \& Vahlne, 2009).

Três características principais do Modelo de Uppsala original foram analisadas: a cadeia de estabelecimento, a distância psíquica aos mercados e o gradualismo na internacionalização. Com relação à cadeia de estabelecimento (Tabela 4), duas empresas apresentam a passagem de um modo de entrada de menor comprometimento (exportação) para um modo de entrada de maior comprometimento, Alfa Piscinas (joint venture) e Usaflex (licenciamento). A Localiza partiu diretamente para o sistema de franquia, não ocorrendo a cadeia de estabelecimento. 
Tabela 4 - Sequência de Modos de Entrada

\begin{tabular}{|l|l|}
\hline \multicolumn{1}{|c|}{ Empresa } & \multicolumn{1}{c|}{ Sequência } \\
\hline Alfa Piscinas & Exportação $\rightarrow$ joint venture de fabricação com franquia máster \\
\hline Localiza & Sistema de Franquia \\
\hline Usaflex & Exportação $\rightarrow$ licenciamento \\
\hline
\end{tabular}

Fonte: Autores.

Quanto à distância psíquica, este fenômeno pode ser observado em vários aspectos das trajetórias das empresas estudadas. Em primeiro lugar, todas escolheram como primeiro mercado países de baixa distância psíquica para o Brasil. Posteriormente, também concentraram sua atuação regionalmente (América do Sul/América Latina). No caso da Alfa Piscinas, única empresa a ter fábricas no exterior, também se caracteriza a implementação inicial em países com distância psíquica pequena em relação ao país de origem da empresa.

O terceiro critério com relação ao modelo de Uppsala original refere-se à adoção de internacionalização gradual ou acelerada. Neste sentido, Alfa Piscinas e Localiza se enquadram mais na característica de gradualismo, já que se internacionalizaram em estágio mais avançado do seu ciclo de vida e processo de internacionalização parece ser na modalidade passo a passo. Já a Usaflex, embora tenha se internacionalizado cedo (cinco anos após sua fundação), iniciou o processo de forma reativa (exportação indireta/direta). Apenas a partir de 2016 moveu-se de forma mais rápida em um processo de internacionalização de maior comprometimento. Também se caracteriza, portanto, como internacionalização gradual.

Desta análise, pode-se dizer que as duas empresas de manufatura examinadas apresentam um comportamento aderente ao modelo de Uppsala original no que se refere à ocorrência da cadeia de estabelecimento, distância psíquica e gradualismo. A Localiza, por sua vez, adere ao modelo no que se refere ao gradualismo e à distância psíquica, mas não à cadeia de estabelecimento.

Três critérios foram utilizados para verificar em que medida os casos estudados apresentam aderência ao Modelo de Uppsala Revisitado (Johanson \& Vahlne, 2009, 2011): uso de parcerias/rede, comprometimento com a rede e aprendizado com a rede. De acordo com Johanson \& Vahlne (2011), a internacionalização gera interdependência e essa relação promove um controle mútuo entre as partes. Desta forma, à medida que uma parceria é desenvolvida, o relacionamento entre as partes se torna interdependente. Em todos os três casos analisados, as empresas desenvolveram novos relacionamentos com parceiros em rede, que permitiram o início e continuidade de seu processo de internacionalização.

Estes relacionamentos podem ter laços fortes ou fracos. De acordo com Granovetter (1973), a força dos laços é uma combinação de quantidade de interações, intensidade, tempo de relação entre as partes e intimidade. Em função das modalidades de entrada escolhidas (franquia e licenciamento), as empresas estudadas buscam desenvolver laços fortes com sua rede imediata (máster franqueados ou licenciados). Nos casos da Alfa Piscinas e da Localiza, por utilizarem o sistema de máster franquia, seus laços com franqueados são mais fracos, pois o relacionamento é primordialmente conduzido pela máster franquia. 
Em todos os casos analisados, detectou-se elevado comprometimento com a rede, que se expressa por meio de investimentos contínuos no relacionamento, por vias formais e informais. De forma consistente com o modelo de Uppsala revisitado, as empresas estudadas relatam haver ocorrido aprendizado recíproco, que contribuiu para construção da confiança mútua. A internacionalização possibilita um aprendizado, o qual pode acontecer de forma experiencial e/ou relacional (Johanson \& Vahlne, 2009) e pode levar à adaptação de produtos/serviços ou até do próprio negócio. Para a Alfa Piscinas, o aprendizado de mercado se salienta como elemento importante dos resultados obtidos. Para a Usaflex, aparecem mais os aprendizados tecnológico e cultural (que se refere tanto ao mercado quanto à rede), enquanto a Localiza enfatiza o aprendizado que traz experiência e visibilidade à empresa.

As empresas também aprendem com os erros cometidos. A Alfa Piscinas relatou que a utilização de brasileiros como coordenadores das operações na Europa e nos Estados Unidos não foi bem aceita. A Usaflex citou que o padrão de qualidade se mostrou diferenciado em função da cultura, o que estimula a empresa a melhorar seus processos continuamente. No caso da Localiza, a falha ocorrida foi relativa ao erro na seleção do franqueado, o que a levou a encerrar momentaneamente operações em dois países.

A aderência dos processos de internacionalização das três empresas estudadas ao Modelo de Uppsala original foi alta para as empresas de manufatura, pois atenderam aos três critérios (cadeia de estabelecimento, distância psíquica aos mercados e gradualismo) e médio para a empresa de serviço, que só atendeu a dois critérios (distância psíquica aos mercados e gradualismo). No Modelo de Uppsala Revisitado todas as empresas preencheram os critérios de uso de parcerias/rede, comprometimento com a rede e aprendizado com a rede (Tabela 5).

Tabela 5 - Síntese da Aderência dos Casos ao Modelo de Uppsala

\begin{tabular}{|l|l|l|}
\hline \multicolumn{1}{|c|}{ Empresa } & \multicolumn{1}{|c|}{ Modelo de Uppsala original (1977) } & \multicolumn{1}{c|}{ Modelo de Uppsala revisitado (2009) } \\
\hline Alfa Piscinas & ALTA & ALTA \\
& $\begin{array}{l}\text { Cadeia de Estabelecimento } \\
\text { Distância psíquica aos mercados } \\
\text { Gradualismo }\end{array}$ & $\begin{array}{l}\text { Comprometimento com a rede } \\
\text { Aprendizado com a rede }\end{array}$ \\
\hline Localiza & MÉDIA & ALTA \\
& Distância psíquica aos mercados & Uso de parcerias/rede \\
& Gradualismo & Comprometimento com a rede \\
& Aprendizado com a rede \\
\hline Usaflex & ALTA & ALTA \\
& Cadeia de Estabelecimento & Uso de parcerias/rede \\
& Distância psíquica aos mercados & Comprometimento com a rede \\
& Gradualismo & Aprendizado com a rede \\
\hline
\end{tabular}

Fonte: Autores.

\section{Discussão}

Este trabalho investigou o papel dos relacionamentos no processo de internacionalização das empresas estudadas à luz dos modelos de Uppsala e dos modos de entrada contratuais. Dos três casos analisados, dois incluem empresas que adotaram o sistema de franquia no exterior e o terceiro se refere a uma empresa que adotou o licenciamento. A Alfa Piscinas e a Localiza utilizaram o sistema de franquia 
para a sua expansão internacional e a empresa de manufatura, Usaflex, utilizou o licenciamento. Nas duas situações, as empresas buscaram reduzir a incerteza (Hoffman, Watson \& Preble, 2016) e os riscos inerentes à atuação internacional, por meio de relacionamentos, como preconizado pelo Modelo de Uppsala Revisitado (Johanson \& Vahlne, 2009).

No caso do uso de franquia, as empresas reduzem os contatos de parceria a um pequeno número de master-franqueados, que, por sua vez, se responsabilizam pela seleção e contato com os demais parceiros. Embora Alon et al. (2015) argumentem que há menor controle e comprometimento quando se usam master-franqueados, isso pode ser verdade para grandes empresas multinacionais, mas não para empresas de porte relativamente menor, como é o caso das empresas estudadas. Para essas últimas, o contato seletivo com máster-franqueados torna possível uma comunicação melhor e possibilita também maior controle, já que não é necessário gerenciar uma multiplicidade de contatos, o que ocorreria se a empresa tivesse que lidar diretamente com cada franqueado. De fato, Jell-Ojobor e Windsperger (2013) chamam a atenção para o fato de que a decisão de usar ou não master-franqueados depende do número de contratos/acordos a serem feitos no mercado internacional visado. Já quando se trata do uso de licenciamento, observou-se a escolha de parceiros direcionada para empresas conhecidas que já importavam produtos da marca e que possuíam conhecimento no setor e uma estrutura bem desenvolvida nos mercados externos. Assim, incerteza e riscos são reduzidos por meio de parcerias em que as licenças são concedidas a parceiros com quem a empresa já realiza negócios e com os quais já estabeleceu laços.

As empresas percebem que, apesar de serem detentoras da marca e do negócio padronizado, a interação com o parceiro local é crucial para o sucesso (como salientaram Kedia et al., 1994). Uma das principais contribuições do parceiro se refere à redução da distância psíquica (Johanson \& Vahlne, 1977), já que por meio da parceria a empresa aprende a lidar com diferenças culturais, de legislação, de como se fazer negócios em um mercado externo, entre outros aprendizados (Alon \& Mckee, 1999; Altinay \& Okumus, 2010; Altinay et al., 2014). Em decorrência desses aprendizados, tornou-se possível para as empresas estudadas realizar adaptações nos produtos e nos modelos de negócios. Além disso, os relacionamentos contribuíram ainda para a inserção das empresas em redes secundárias, criando mais laços fracos que suportam a circulação de conhecimento (Johanson \& Mattson, 1993). A ampliação das redes em que as empresas estavam inseridas, por meio dos contatos proporcionados pelos parceiros, mostraram-se importantes na continuidade da internacionalização das empresas estudadas. O relacionamento com os parceiros nas empresas estudadas mostra-se consistente com as recomendações que emanam da literatura, envolvendo confiança comprometimento e compartilhamento de conhecimento (Altinay et al., 2014; Davies et al., 2011; Rosado-Serrano, Paul \& Dikova, 2018) e estão de acordo com as proposições do Modelo de Uppsala Revisitado. 


\section{Considerações finais}

Os resultados do estudo mostram que a internacionalização das empresas franqueadoras estudadas pode ser explicada tanto pelo Modelo de Uppsala original quanto pelo Modelo de Uppsala revisitado, e que as duas explicações são compatíveis. No entanto, enquanto só a internacionalização de duas empresas adere plenamente aos pressupostos do modelo original, todos os processos aderem fortemente ao modelo revisitado. A ausência da cadeia de estabelecimento no processo de internacionalização de uma das empresas se deve em grande parte a se tratar de uma empresa de serviços.

O estudo apresenta limitações que devem ser consideradas. A primeira deriva do uso da metodologia de estudo de casos, que não permite generalizações estatísticas para além dos casos estudados. A segunda se refere ao fato de terem sido estudadas apenas três empresas, embora se trate de casos significativos, por sua importância como franqueadoras. Mesmo assim, é possível que o estudo de franqueadoras menores ou mais jovens possa produzir resultados distintos daqueles aqui apresentados, ou seja, que o modelo de Uppsala, em suas duas versões, não apresente aderência a casos distintos dos examinados. Novos estudos poderão trazer contribuições significativas ao entendimento do processo de internacionalização de empresas franqueadoras brasileiras e de outros países emergentes.

\section{Referências}

ABF (2018, 18 maio). Números do Franchising / Desempenho do setor. Associação Brasileira de Franchising. Disponível em: https://www.abf.com.br/numeros-do-franchising/.

Aguiar, H.D.S., Consoni F.L., \& Bernardes R.C. (2014). Estratégia de internacionalização conduzida: Um estudo em redes de franquias brasileiras. RECADM - Revista Eletrônica de Ciência Administrativa, 13(1), 114-131.

Aliouche, E.H., \& Schlentrich, U.A. (2011). Towards a strategic model of global franchise expansion. Journal of Retailing, 87(3), 345-365.

Alon, I., Boulanger, M., Misati, E., \& Madanoglu, M. (2015). Are the parents to blame? Predicting franchisee failure. Competitiveness Review, 25(2), 205-217.

Alon, I., \& McKee, D. L. (1999). The internationalization of professional business service franchises. Journal of Consumer Marketing, 16(1), 74-85.

Altinay, L., Brookes, M., Yeung, R., \& Aktas, G. (2014). Franchisees' perceptions of relationship development in franchise partnerships. Journal of Services Marketing, 28(6), 509-519.

Altinay, L. \& Okumus, F. (2010). Franchise partner selection decision making. The Service Industries Journal, 30(6), 929-946.

Baena, V. (2018). International franchise presence and intensity level: Profile of franchisors operating abroad. Management Research Review, 41(2), 202-224.

Borini, F.M., Rocha, T.V., \& Spers, E.E. (2012). Desafios para a internacionalização das franquias brasileiras: um survey com franquias internacionalizadas. In: Melo, P.L.R. \& Andreassi, T. (Orgs.). Franquias Brasileiras: estratégia, empreendedorismo, inovação e internacionalização. São Paulo: Cengage Learning. 
Borini, F., Souza, M., Biskamp, S., Coelho, F., \& Sadzinski, A. (2013). A influência dos traços da cultura brasileira no processo de internacionalização das franquias nacionais. Gestão Contemporânea, 10(13), 313-338.

Bretas, V.P., Galetti, J.R., \& Rocha, T.V. (2019). Fatores relacionados a internacionalização das redes de franquias brasileiras: dispersão geográfica e pertencimento a grupos. InterNext - Revista Brasileira de Negócios Internacionais, 14(1), 1-13.

Brookes, M., \& Altinay, L. (2011). Franchise partner selection: Perspectives of franchisors and franchisees. Journal of Services Marketing, 25(5), 336-348.

Brookes, M., \& Altinay, L. (2017). Knowledge transfer and isomorphism in franchise networks. International Journal of Hospitality Management, 62, 33-42.

Brouthers, L.E., \& McNicol, J.P. (2009). International franchising versus licensing. In: Kotabe, M. \& Helsen, K. (Org.). The Sage Handbook of International Marketing. London, Sage, p.183-197.

Cavusgil, S. T. (1998). Perspectives: knowledge development in international marketing. Journal of International Marketing, 6(2), 103-112.

Dant, R.P. \& Grünhagen, M. (2014). International franchising research: Some thoughts on what, where, when, and how. Journal of Marketing Channels, 21, 124-132.

Davies, M., Lassar, W., Manolis, C., Prince, M., \& Winsor, R. (2011). A model of trust and compliance in franchise relationships. Journal of Business Venturing, 26(3), 321-340.

Eisenhardt, K. M. (1989). Building theories from case study research. Academy of Management Review, 14(4), 532-550.

Evans, J., Treadgold, A., \& Mavondo, F. T. (2000). Psychic distance and the performance of international retailers - A suggested theoretical framework. International Marketing Review, 17(4/5), 373-391.

FDC - Fundação Dom Cabral (2017). Ranking de Internacionalização das Franquias Brasileiras. São Paulo, Fundação Dom Cabral.

Ghauri, P. (2004). Designing and conducting case studies in international business research. In: Piekkari, R. \& Welch, C. (Eds.), Handbook of Qualitative Research Methods for International Business. Cheltenham, UK: Edward Elgar Publishing, pp. 109-124.

Gomes, R.M.A., Carneiro, J.M.T., \& Secches, C.K. (2017). Estudos de caso na internacionalização varejista: uma revisão de literatura. InterNext - Revista Brasileira de Negócios Internacionais, 12(1), 16-32.

Granovetter, M. (1973). The strength of weak ties. American Journal of Sociology, 78(6), 1360-1380.

Guetta, A., Von Jess, A.C., Filho, B., Gudiño, D., et. al. (2013). Franchising: Aprenda com os Especialistas - Learn from the Experts. Rio de Janeiro, Associação Brasileira de Franchising.

Hoffman, R. C., Watson, S., \& Preble, J. F. (2016). International expansion of United States franchisors: A status report and propositions for future research. Journal of Marketing Channels, 23(4), 180-195.

IFA (2018, 25 maio). Franchise Business Economic Outlook for 2018. International Franchise Association. Disponível em: https://www.franchise.org/sites/default/files/Franchise_Business_Outlook_Jan_2018.pdf 
Isaac, V.R., Melo, P.L.R., Ogasawara, M.H., \& Rodrigues, T.R. (2018). Metanálise sobre publicação nacional e internacional sobre internacionalização de redes de franquias. Revista da Micro $e$ Pequena Empresa, 12(1), 82-95.

Jell-Ojobor, M., \& Windsperger, J. (2014). The choice of governance modes of international franchise firms - development of an integrative model. Journal of International Management, 20(2), 153187.

Johanson, J., \& Mattson, L.-G. (1993). Internationalization in industrial systems - a network approach. In: Buckley, P.J; Ghauri, P. (eds). The Internationalization of the Firm: A Reader. London, Academic Press, p. 303-321.

Johanson, J., \& Vahlne, J.-E. (1977). The internationalization process of the firm - a model of knowledge development and increasing foreign market commitments. Journal of International Business Studies, 8(1), 23-32.

Johanson, J., \& Vahlne, J. E. (1990). The mechanism of internationalisation. International Marketing Review, 7(4), 11-24.

Johanson, J., \& Vahlne, J. E. (2009). The Uppsala Internationalization Process Model revisited: From liability of foreignness to liability of outsidership. Journal of International Business Studies, 40(9), $1411-1431$.

Johanson, J, \& Vahlne, J. E. (2011). Markets as networks: Implications for strategy-making. Journal of the Academy of Marketing Science, 39(4), 484-491.

Johanson, J., \& Wiedersheim-Paul, F. (1975). The internationalization of the firm - Four Swedish cases. Journal of Management Studies, 12(3), 305-323.

Kedia, B.L., Ackerman, D.J., Bush, D.E., \& Justice, R.T. (1994). Determinants of internationalization of franchise operations by US franchisors. International Marketing Review, 11(4), 56-68.

Marques, D., Merlo, E., \& Nagano, M. (2009). Uma análise sobre internacionalização de franquias brasileiras. Read: Revista Eletrônica de Administração, 62(15), art 1. Edição 62, V. 15, № 1.

Quinn, B., \& Alexander, N. (2002). International retail franchising: A conceptual framework. International Journal of Retail \& Distribution Management, 30(5), 264-276.

Tang, Y. K. (2009). Networks and the internationalization of firms: What we believe and what we might have missed. In: Jones, M., Dimitratos, P., Fletcher, M., \& Young, S. (Org.). Internationalization, Entrepreneurship and the Smaller Firm. Edward Elgar, Cheltenham, p. 106123.

Vianna, N.W.H., Melo, P.L.R., \& Ryngelbaum, A.L. (2014). Processo decisório de internacionalização de redes de franquias brasileiras. InterNext - Revista Brasileira de Negócios Internacionais, 9(1), 101-118.

Welch, L. S. (1989). Diffusion of franchise system use in international operations. International Marketing Review, 6(5), 7-19.

Yin, R. K. (2009). Case Study Research. 4 Ed. Thousand Oaks, CA, Sage. 